\title{
Learning at the Nanoscale: The Impact of Students' Use of Remote Microscopy on Concepts of Viruses, Scale, and Microscopy
}

\author{
M. Gail Jones, ${ }^{1}$ Thomas Andre, ${ }^{2}$ Richard Superfine, ${ }^{3}$ Russell Taylor ${ }^{4}$ \\ ${ }^{1}$ School of Education, University of North Carolina at Chapel Hill, Chapel Hill, \\ North Carolina 27599-3500
}

${ }^{2}$ Department of Curriculum and Instruction, N131 Lagomarcino Hall, Iowa State University, Ames, Iowa 50011-3190

${ }^{3}$ Department of Physics and Astronomy, University of North Carolina at Chapel Hill, Chapel Hill, North Carolina 27599-3255

${ }^{4}$ Department of Computer Science, University of North Carolina at Chapel Hill, Chapel Hill, North Carolina 27599-3175

Received 8 January 2002; Accepted 28 August 2002

Abstract: The rapid pace of development is bringing advanced technologies to the World Wide Web (WWW), and, as a result, schools have access to new tools for science investigations. In this exploratory study, we investigated how an educational experience organized around students' use of a WWWcontrollable atomic force microscope (AFM) influenced students' understandings of viruses. The context for the study was a weeklong unit on viruses for two high school biology classes which incorporated student use of the WWW controllable AFM. We also investigated how the haptic (involving kinesthetics and touch) experiences afforded by this tool might influence students' knowledge of viruses, microscopy, and nanometer scale. Fifty students from two high school biology classes participated in a series of instructional activities and pre- and postassessments (knowledge test, opinion questionnaire, and interviews). Results showed that students' understandings of microscale, virus morphology, and dimensionality changed as a result of the experiences. Students' conceptions moved from a two-dimensional textbook-like image of a virus to a three-dimensional image of an adenovirus. The results of this preliminary study suggest that the use of the technology as a tool for learning about morphology of materials too small to see may be beneficial. (C) 2003 Wiley Periodicals, Inc. J Res Sci Teach 40: 303-322, 2003

\footnotetext{
Contract grant sponsor: University of North Carolina Research Council; Contract grant sponsor: National Science Foundation; Contract grant number: REC-0087389.

Correspondence to: M. Gail Jones; E-mail: gjones@email.unc.edu DOI 10.1002/tea.10078

Published online in Wiley InterScience (www.interscience.wiley.com).
} 
In this exploratory study, we investigated the educational use of a new technological innovation called nanoManipulator $(\mathrm{nM})$ that allows for the control of an atomic force microscope (AFM) over the World Wide Web (WWW). The $\mathrm{nM}$ consists of a microcomputer programmed to control a joystick-like device that can provide tactile feedback and software that converts the output of an AFM into a three-dimensional visual image on the computer screen and tactile feedback provided by the joystick device (Figure 1). The nM can be connected to the AFM over the Internet. Using this device, students can investigate nanometer-size materials located at a university. There are two unusual components to this technological tool: (a) students can actually get tactile feedback from the $\mathrm{nM}$ about the properties of the object being studied, and (b) they can investigate and manipulate objects that are nanometer-size (1/1,000,000,000 of a meter). The $\mathrm{nM}$ is a haptic tool because it involves students in physical manipulations (kinesthetics) and provides tactile feedback. For the first time, through the use of this new technology, students can have hands-on experiences with objects at the nanometer scale-objects that are too small to be seen or touched otherwise.

The study of nanoscience is one of the fastest growing areas of science. Mere science fiction a decade ago, today's nanotechnology advancements allow scientists to image individual atoms, move atoms, and create nanoscale robots and storage devices as small as $50 \mathrm{~nm}$ in diameter, nanowheels that rotate, and a nanosize abacus with single molecules as the sliding beads (Rotman, 1999). Biologists are exploring the potential of nanosize machines serving as superintelligent diagnostic probes (Piller, 2000).

Now students can investigate nanoscale science through the nM. The tool's capacity to provide students with tactile feedback about very small materials raises questions about how it may be useful in improving students' conceptions of microscopic objects. When using the nM, students move a penlike joystick that sends signals to move a probe in the AFM. The microscope probe moves across a sample (such as a virus) and the changes in the deflection of the probe are detected by the microscope, amplified, and sent back to the user across the Internet. The nM translates these signals into motion in the penlike joystick. Thus, the student can feel the probe travel over the surface of the sample. The tactile feedback includes sensations of hardness, elasticity, friction, morphologic shape, and stickiness. The $\mathrm{nM}$ also uses virtual reality technology to provide a visual three-dimensional image in a video monitor of the sample that is being examined. Thus, the user can both see and feel objects that have been magnified 200,000 times.

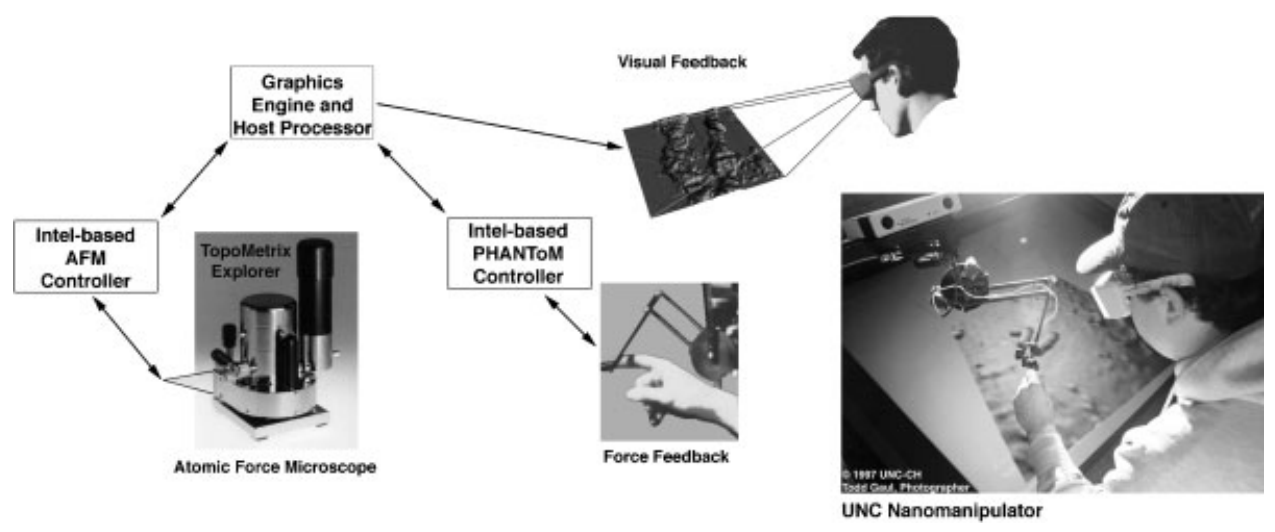

Figure 1. NanoManipulator. 
The combination of physical manipulations and tactile feedback provides the student with haptic perception.

\section{Literature Review}

Haptics. Haptic researchers have noted that, unlike sight, touch involves intentional movement of the learner (Katz, 1989). Haptic perception provides the learner with information about viscosity, softness, texture, elasticity, graininess, pressure, and temperature, and involves kinesthetics (muscle, tendon, and joint). Klatzky, Lederman, and Reed (1987) noted that haptics is oriented toward the encoding of substance (microstructure), whereas vision is oriented toward the encoding of shape (macrostructure). Recent research by Heller, Calcaterra, Green, and Brown (1999) showed that haptics is also oriented toward encoding shape, and shape understanding is one of the key elements of $\mathrm{nM}$ investigations.

Science educators have historically recognized the value of hands-on experiences and learning by doing. It is possible that part of the value of hands-on experience and learning by doing involves the haptic sensations and their encoding. When objects are too small to be seen with the unaided eye, hands-on learning typically involves using simulations and models. The nM technology removes a layer of abstractness by providing a seemingly direct experience of both seeing and touching while manipulating microscopic objects. Thus, students are able to have hands-on experiences with Bucky Tubes, viruses, and molecules such as DNA.

Experiences such as these raise questions about how students encode haptic perceptions in memory. Paivio's dual coding $(1971,1986)$ theory argues that experiences can be represented in both an image-based memory and verbal (linguistic) memory. Linked image and verbal representations provide better remembered, more integrated knowledge that facilitates problem solving. Encouraging students to create linked image and linguistic representations thus facilitates science learning (Paivio, 1986; Pressley \& McCormick, 1995). Helping students develop imagery and linguistic mental models facilitates learning of scientific content (Mayer et al., 1989, 1994, 1995, 1996; Paivio, 1986; Rieber, 1990, 1991, 1995; Windschitl \& Andre, 1998; Yang, Greenbowe, \& Andre, 1999). Whereas most of the research on Paivio's theory has focused on visual images, images can have a broader meaning. There is no generic English word for sensorylike mental representations or structures. The term image has been used for this concept (Andre \& Phye, 1986). Thus, haptic, action-related experience, as well as visual experience, can be represented in mental experiential images. By providing haptic as well as visual feedback, the nM technology provides students with the opportunity to combine visual and verbal representations with haptic.

Thus far, this discussion finesses a number of theoretical issues. One of them involves the relationship between Paivio's visual store and Tulving's episodic memory (Tulving, 1972). In Tulving's concept, episodic memory retained information about the sensory aspects of personal experience. Recall from episodic memory gave one a subjective but conscious sense of reexperiencing the event or episode. While aware that this is a memory, individuals report that the experience has sensory properties. Such sensory properties are more than visual. Ask individuals to recall whether the doorknob in their usual entrance to a previously lived-in house was on the right or left. In any large sample, many will reach out physically for the mental doorknob and will move their eyes in its direction. The recall of tactile/haptic information is greater when the recalled episode is more tactile/haptic in nature. Ask individuals to recall the feeling of a skiing episode or a memorable meal and they will report tactile/haptic or gustatory sensations. For the present purposes, differences in theoretical models from cognition or neural science are irrelevant. 
What is important is that sensory properties of experience may enhance the educational experience.

\section{Technology-Mediated Inquiry}

Technological innovations have opened new worlds of science for students to explore. Yet, as the development of new scientific technologies accelerates, research on the use of these technologies in instruction lags. Instructional technology has moved from the early computer software that was limited to serving as drill and practice, to new interactive technologies that enable students to step into the role of the scientist by conducting experiments, collecting and analyzing data, and collaborating with other investigators around the world. This evolution has followed a continuum from those that are strictly individual informative tools, to individual constructive tools, to social communicative tools, to the new generation of technological tools that allow for social construction of knowledge. According to Hung and Chen (1999), this last generation of technological designs allows for the social nature of learning critical for the negotiation of meaning by students.

Science classes around the world have become involved in Internet-based investigations such as the JASON Project and Journey North. At one end of the spectrum, students observe ongoing research through projects such as WhaleNet, the Rain Forest Connection, Elephants of Cameroon, and the Center for Biological Timing (e.g., http://njnie.dl.stevens-tech.edu/cyberteacher/ realtimeprojects.html). The next level of instructional complexity involves students in collecting and analyzing data and interacting with scientists and other students (see, for example, the CoVis Project and GLOBE).

These more recent Internet-based science programs move students along the continuum away from using computer technology as an information source to using the computer as a vehicle for conducting and sharing science. According to the American Institute of Physics Panel on Using Technology for Education (American Institute of Physics, 1997), as well as Linn, Shear, Bell, and Slotta (1999), educational technology should do the following: (a) focus on learning with technology, not about technology; (b) emphasize content and pedagogy, not just hardware; (c) provide accessible goals so students can connect new ideas with those they already have; (d) ensure the social context of learning supports the process of building on ideas of others; and (e) promote autonomy by creating learners who can move on into life with new skills and knowledge.

According to the National Science Education Standards: "Students at all grade levels and in every domain of science should have the opportunity to use scientific inquiry and develop the ability to think and act in ways associated with inquiry" (National Research Council, 1996, p. 105). The $\mathrm{nM}$ allows students to use cutting-edge technology as advocated by the Panel on Using Technology for Education by learning with technology as students ask original questions that are only now being explored by scientists.

\section{Method}

In this exploratory study, in addition to examining how the overall nM-AFM experience would influence students' understanding of viruses, we sought to understand how the presence or absence of haptic feedback might influence students' conceptions of viruses. As specified below, one class received full haptic feedback while a second received limited haptic feedback from the $\mathrm{nM}$. We explored how this manipulation might influence student conceptions and how the differences between the full and limited haptic groups might be assessed. We administered paper 
and pencil tests dealing with viruses, microscopy, and nanoscale because we wanted to determine improvements in students' knowledge in these areas. However, because both groups received full three-dimensional visual images and both groups participated in the other educational activities, we felt that these paper and pencil tests might not show differences between the groups. For these reasons, we also asked all students to describe verbally and draw viruses and to write newpaper stories about their experiences. In addition, we asked a targeted subset of students to participate in detailed interviews and to construct clay models of viruses. We felt that students who received the full haptic feedback might describe or represent the viruses in ways different from students who received limited haptic feedback. For example, students who received full feedback might have been more likely to describe what the virus felt like in their descriptions or stories or might have more concerned with including surface features in their drawings or models. Finally, we believed that students who received full feedback might be more interested in and excited by the educational experience. For this reason, we assessed the students' affective and attitudinal reactions as well. Although potentially useful for detecting differences between the full haptic feedback and limited haptic feedback groups, these assessments were also useful for detecting the impact of the educational experience on both groups. Thus, the study had two research questions: (a) How does the AFM-nM-based educational experience affect students' learning? and (b) How does the haptic feedback afforded by the AFM-nM experience influence students' conceptions of viruses?

\section{Participants}

The participants were 24 male and 26 female students in two Introductory Biology classes $(n=22, n=28)$ in a rural-suburban high school in the central region of North Carolina. Biology classes were selected because it is a subject required of all students in North Carolina and includes the study of viruses. Because of the flexibility of the school's curriculum, 21 students were sophomores (10th grade), 25 were freshmen (9th grade), and 4 were juniors (11th grade). The school serves a wide socioeconomic range. Our sample included students whose parent(s) were laborers and students whose parents had professional level occupations. The demographics of the school included 72\% Euro-American, 24\% African-American, 3\% Hispanic students, and $1 \%$ Other. The biology classes were chosen because the teacher was interested in incorporating technology in her classroom and was willing to have the students participate in the experiment. In addition, the biology curriculum included the study of viruses later in the year and this experience would serve as a early introduction to that unit.

In each class, approximately half the students ( 6 males, 6 females) were studied for intensive qualitative research (the number was determined by the number of available field researchers). These individuals were closely observed during the learning experience with the AFM-nM, and extensive pre- and postinterviews with these students were conducted.

\section{Instruments}

The instruments were pilot-tested in a previous study (Jones, Superfine, \& Taylor, 1999). These assessments are described in Table 1 and the sections that follow.

Pre-Knowledge Test (PKT). The PKT was developed by the researchers to assess students' fundamental knowledge of viruses. It contained four constructed response items. Students were asked to describe what they knew about viruses and what viruses looked like, describe how viruses function, describe a nanometer and things that could be measured in nanometers, tell how viruses 
Table 1

Assessment overview

\begin{tabular}{llcc}
\hline \multirow{2}{*}{ Assessment } & \multicolumn{3}{c}{ Domains Assessed } \\
\cline { 2 - 4 } & & Preinstruction & Postinstruction \\
\hline Knowledge Test & Concepts (viruses, Scale) & $\mathrm{X}$ & $\mathrm{X}$ \\
Opinion & Beliefs, attitudes & $\mathrm{X}$ & $\mathrm{X}$ \\
Experience & Attitudes, beliefs, prior experiences & $\mathrm{X}$ & $\mathrm{X}$ \\
Interview & Concepts (microscopy, viruses, scale) & $\mathrm{X}$ & $\mathrm{X}$ \\
Clay model task & Virus morphology & $\mathrm{X}$ & $\mathrm{X}$ \\
\hline
\end{tabular}

cause disease, and draw a picture of a virus. We wanted to solicit whatever information students believed about viruses. Therefore, students were told that because we were interested in "any ideas you might have," they should respond to each of the questions even if they felt what they wrote was a guess.

Pre-Opinion Questionnaire (PROQ). The scale contained items that asked students rate their reactions to working with a microscope. Students rated their reactions on a 6-point Likert scale that ranged from "very true of me" to "very untrue of me." Appendix A contains a list of these items.

Post-Knowledge Test (POKT). The POKT included constructed response questions that asked students to describe the nM and AFM, identify and describe different types of microscopes, describe an adenovirus, list things that could be measured in nanometers, list things that would measured in micrometers, and draw a virus. These items were chosen to assess changes in students' knowledge from the pretest and assess knowledge of topics covered in the instructional experience.

Post-Experience Questionnaire (EQ). The EQ contained five constructed response items. Students were asked to describe whether and how the instructional experiences influenced how they felt about doing science. They were asked to describe additional experiments they would have performed with the AFM.

Post-Opinion Questionnaire (POOQ). The POOQ included the 8 reaction items from the PROQ and 2 additional rating items. These latter 2 items are presented in Appendix A. The items asked students to rate how much they had learned and how much the instructional experience had changed their views of learning.

Pre- and Postinterview Questionnaire. The pre- and postinterview questionnaire contained a series of questions that guided our intensive interviews with the purposive subsample of students. The items asked about characteristics of the AFM and nM, the characteristics of the adenovirus, how big viruses were, and about students' perceptions of the learning experiences. These items were used to initiate the interactions with the students. The interviewers followed up on student responses to probe their understandings and reactions more deeply than could be done with written response assessments. The items on the pre- and postinterviews are listed in Appendix B. In addition, during the pre- and postinterviews, students were asked to construct and explain a clay model of a virus. 


\section{Equipment}

The students used a Phantom nM device connected to a desktop computer to access, over the Internet, an AFM located at the University of North Carolina. An nM is a penlike device that uses internal electric motors to provide tactile feedback from the AFM. Information is sent from the AFM to the microcomputer connected over the WWW. As the AFM sensing tip moves over a sample, changes in its elevation are detected by a laser. The computer control system translates these elevation changes into commands to the $\mathrm{nM}$. The motors in the $\mathrm{nM}$ move and give the person holding the device the sensation of holding a tracing pencil that goes up and down. In effect, the person can feel the object being sensed by the AFM. The sensation is similar to holding a pencil and tracing it over an irregular surface such as a coin. While controlling the AFM tip manually, it is possible to move a virus by pushing and to push the tip into the viral protein shell and break it open.

\section{Design}

This study was designed to assess the impact of a weeklong educational experience using the $\mathrm{nM}$ and AFM on students' understandings of viruses, microscopy, and nanometer scale. We also wanted to examine the impact of receiving or not receiving tactile feedback from the AFM on students' understanding of virus morphology. We were interested in exploring whether feeling an object that you cannot ordinarily see with the unaided eye would alter an individual's conception of that object.

Students in one of the two classes were randomly assigned to the full-tactile condition. Students in the other class were assigned to the nontactile condition. Control of the tactile stimulation was obtained through a software switch that led the software either to send or not send the appropriate tactile signals to the nM. Because control of the AFM tip is difficult without tactile feedback, the students in the nontactile condition received a limited tactile response. The software responded when the AFM touched the surface on which the virus samples were resting. Students could feel a flat plane but the undulations in the surface caused by the viruses were not felt. The students in the full tactile condition could feel both the surface and the viruses.

\section{Procedure}

Approximately 1.5 months before the start of the instructional activity, participants received an explanatory letter and permission forms. Approximately 2 weeks later, participants completed the PKT and PROQ. The students were assessed in their assigned class. The basic purpose of the study was described and students completed the assessments independently.

Instructional Activity. The instructional activities occupied five science class periods. At the beginning, students were told that they would be asked to write a newspaper article on their experiences and that the article would be published in a Web newspaper. An activity packet provided directions for each of the activities described below and gave the students suggestions for making notes for their newspaper article. On the first day, the students received whole-class instruction from one of the participating scientists in the AFM project. The instruction covered metric scale from the macroscopic to the microscopic, the nature of microscopes (light, scanning electron, and atomic force) and provided an in-depth description of how the nM and AFM work to provide magnified images and tactile feedback. On each of the next 3 days, the classes were divided into teams of 4 or 5 students. In each class, three of the teams consisted of students in the purposive sample. Because of differences in class sizes, one class contained 5 teams and one class 
6. Over the 3 days, each team completed two activities per day with each activity lasting for 2025 minutes. The activities were: use nM-AFM, use a mechanical simulation of the AFM, interview a scientist I, interview a scientist II, writing I, and writing II (described further in the sections that follow).

$n M-A F M$. In this activity, each student had the opportunity to use the nM-AFM under the guidance of an experienced physics researcher. Each student was allowed to control the nM to touch a virus and use the $\mathrm{nM}$ to make individual investigations such as moving viruses on the stage, trying to push the AFM probe into a virus, or breaking the protein coat of the virus. Each student received tactile feedback appropriate for her or his treatment group.

The nM-AFM station consisted of the Phantom nM device and a desktop microcomputer that controlled the Phantom and was linked to the AFM over the WWW. A second computer and phone connection were also used to provide a visual and auditory link to the AFM laboratory at the university where a scientist worked to make sure the link and equipment functioned. The students were allowed and encouraged to talk to the scientists, particularly while one of their team members was using the AFM. For most of the students, this was their first experience with two-way visual communication over the WWW.

Simulator Activity. The simulator activities consisted of a mechanical model of the AFM. The model allowed a tip to travel across a stage and over a sample. An unfolded outline of an icosohedron was produced on a sheet of paper. Students cut out the outline and used it to make a three-dimensional model of an adenovirus. A completed model was approximately the size of a softball. The protein projections (spikes) of an adenovirus were not included in the model (Figure 2).

Students also uncoiled a 10-meter length of yarn and inserted it into their virus. The yarn represented DNA. The point of this activity of building the model was to reinforce students' understanding of scale of cells and viruses. The students had been told that if a human cell were magnified 1,000,000 times it would be about the size of their classroom. An adenovirus magnified $1,000,000$ times would be about the size of a softball. This magnified adenovirus would contain

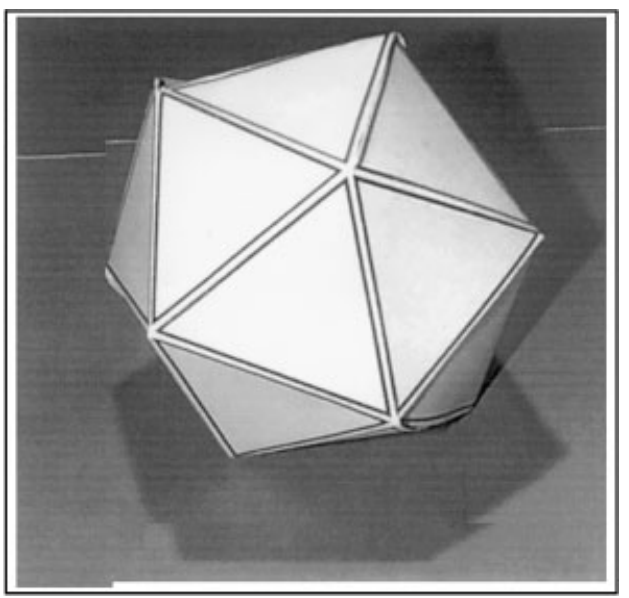

Figure 2. Paper adenovirus. 
approximately $10 \mathrm{~m}$ of DNA. Constructing the model and comparing it with the size of the classroom gave the students the opportunity to appreciate the relative sizes of the objects. Coiling the yarn into their model was designed to give the students some appreciation for the coiling of the DNA in a virus.

Once the models were constructed, students completed a tracing of their model adenovirus with the simulator. The purpose of the activity was to demonstrate how only the surface of objects can be imaged with the AFM and that the sides of the virus are masked by the nature of the device. The scientist in charge of demonstrating the AFM simulator also had two tips available for the simulator (a wide cone and a narrow cone) and at least one member of each team completed a tracing with a different tip. The scientist asked probing questions to help students perceive the difference in the tracings, (e.g., Why does the fatter tip produce a less accurate tracing?) and to assist the students in relating the simulator experience to the AFM activity.

Interview A Scientist. Students had at least two opportunities to interview scientists who conduct research on nanoscience topics. A variety of scientists were involved and included physicists, information scientists, and computer scientists.

Writing Activity/Newspaper Reports. In the writing activity, students had the opportunity to plan and write a newspaper story. Students were provided with a possible outline of a typical newspaper report, but were also encouraged to be creative in the story they prepared. Students were asked to give readers a description of what they personally found worth noting about the experiences. That is, students were encouraged to write about their personal reactions to the $\mathrm{nM}$ and AFM activities. There is evidence that writing for a nonteacher audience can facilitate students' conceptual understandings of science topics (Prain \& Hand, 1999) and this activity was included to enhance the educational benefits of the overall instructional activities. In addition, we believe that the students would provide a rich source of data about the understanding of the science and their reactions to the experience.

Posttest Activities. On the fifth day, students completed the postassessment instruments (POKT and POOQ) and their newspaper stories.

Individual Interviews. The students in the subsample were interviewed individually approximately 2 weeks before the instructional week. The first two authors conducted the interviews. Each individual interview took approximately 15 minutes. Interviewers followed the interview protocol listed in the Appendix but pursued items in more depth if that seemed likely to yield more information. Interviews were audiorecorded and the observer also made field notes. During the interview, students were asked to construct a clay model of a virus. The clay models were videotaped to record their structure.

Postinterviews were conducted in a manner similar to the preinterviews during the week after the instruction. Interview audiotapes were transcribed and used as part of the analyses below.

\section{Analyses}

The analyses used the following data sources: the knowledge test (pre and post), the opinion questionnaire (pre and post), the experience questionnaire (post), the interview questionnaire (pre and post), the design of a clay model virus (a component of the pre- and postinterview), and the newspaper stories written by the students. 
The analyses focused on students' understandings of viruses, microscopy, and scale. The knowledge test, opinion questionnaire, and interview questions were analyzed by item for pre- and postassessments. Interview tapes were transcribed and pre- and postinstruction item responses were placed in a matrix for comparison. Frequencies of responses for each item on the knowledge tests, opinion questionnaires, and interviews were determined, and for open-ended items, student responses were grouped into categories (described further with the Results).

\section{Clay Model}

The videotapes of the clay models were digitized and each model was observed from several angles and written descriptions were made. Categories of analysis for the models were developed to code morphologic attributes. These categories included: angles, two dimensions, three dimensions, irregular edges, bumps or dimples, appendages, 20-sided, spherical and angled (like the paper model students constructed) (Figure 2), cell-like, phagelike, rounded icosohedral (like the microscope image they saw on the computer monitor) (Figure 3), ball-shaped, and amoebalike.

\section{Newspaper Reports}

The newspaper reports were read and reread across individuals and categories of analysis were identified by the major areas addressed in the stories. For this study, the categories that emerged and were subsequently coded included: references to feeling or manipulating the virus ("tracing," "moving the virus," or "squishing the virus"), descriptions of the shape or texture of the virus ("lumpy," "round," or "20-sided"), descriptions of affective reactions to the experiences ("cool," "nice," or "weird"), and references to changes in students' ideas or opinions ("I learned..." "They taught me..." or "I never knew..."). Two readers independently read and rated all the reports $(n=43)$ for an overall interrater coding agreement of $84 \%$. The frequencies of each coded category were obtained and patterns of responses were examined across students.

\section{Results}

With respect to the first research question, exploring the impact of the AFM-nM experience on the students' conceptions, the knowledge tests, opinion questionnaires, and interview questions

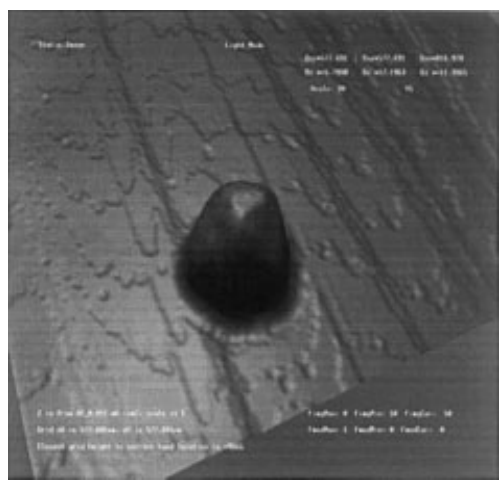

Figure 3. Atomic force micrograph of an adenovirus. 
revealed changes in students' knowledge of viruses, microscopy, and nanometer scale. Each of these areas is described in the sections that follow. With respect to the second research question, investigating the limited versus full haptic feedback influence student conceptions, we were unable to detect differences. We discuss these results first, followed by a discussion of the combined data in assessing the overall impact. Univariate group by gender analyses of variance (ANOVAs) on the pretest scores and posttest scores indicated no significant differences between the classes (students in one class received full tactile feedback and students in the other received only modified feedback). This second group of students could manipulate the viruses but received only limited tactile sensations from the nM. On common items on the preknowledge and postknowledge tests, the mean number of items correct for students in the class not receiving tactile feedback were $5.6 \%$ and $52.8 \%$, respectively. For the class with full tactile feedback, the parallel means were $4.8 \%$ and $52.4 \%$, respectively. Gender and the interaction of gender and group were also not significantly different for either the pretest or posttest data. Most of the students had scores of zero on the pretest. Performance was so low on the pretest that the ANOVA is questionable because the distributions are extremely different from the normal distribution. Follow-up chi-square analyses comparing students who received 0 versus any points also failed to reveal significant differences for gender and group on the pretest. It seems neither the groups nor the genders differed significantly on the pretest because most students knew little about viruses. The groups and genders also did not differ on the univariate posttest or on a follow-up analysis of the posttest in which pretest score was used as a covariate. For these reasons, group and gender were ignored in analyses of performance on the individual pre- and posttest items discussed below (pretest and posttest correlated .37, $p<.05$ ). As the reported means described above suggest, students appeared to improve from pretest to posttest. A repeated measures ANOVA of pretest to posttest scores (including only the common items) indicated a significant increase in performance from pretest to posttest, $F(1,35)=105.4, p<.0001$ (mean pretest $5.1 \%$, mean posttest $52.6 \%$ ). Although this analysis is also questionable because of the nonnormality of the pretest distribution, it is reported here merely to support the impression that students improved from pretest to posttest. Follow-up analyses of performance on individual items, using the Chi-square statistic that does not require distributional assumptions, confirm this proposition.

Qualitative analyses of students' drawings, responses, and clay models also found no differences between the two classes. Again however, there were pre- and postdifferences that occurred; these results are described in the sections that follow.

\section{Knowledge of Viruses}

Data from multiple sources were used to assess changes in students' understandings of the morphology of viruses. The knowledge tests asked students to provide a written description of the structure of viruses ("What do they look like?"), draw a virus, and describe how viruses function. During the interviews, students were asked again to describe a virus and make a clay model of a virus. These different sources of data provided evidence of students' conceptions of viruses before and after the investigations.

Before instruction, most students had limited concepts of the structure of viruses, typically representing viruses as similar to cells or amoebas. When asked what viruses look like, typical students responses included: "I guess it looks like a cell with ridges on it" (Tracy), "They look like a human cell but they swallow our cells" (Kathy), and "Circular shape or stringy look" (Sam). The drawings of the viruses before the instruction tended to look like the images of amoebas or cells typically found in science textbooks (discussed further in the sections that follow). 
Table 2

Frequencies of clay model virus attributes

\begin{tabular}{lcc}
\hline Attribute & Preinstruction & Postinstruction \\
\hline Angled & 3 & 13 \\
2D & 16 & 7 \\
3D & 8 & 16 \\
Irregular & 6 & 4 \\
Bumps/dimples & 14 & 6 \\
Appendages & 2 & 2 \\
Angular sphere & 0 & 10 \\
20-sided & 0 & 5 \\
Cell-like & 2 & 0 \\
Phagelike & 2 & 2 \\
Rounded icosohedral & 0 & 1 \\
Round & 5 & 1 \\
Amoebalike & 2 & 4 \\
Cilliatelike & 0 & 0 \\
\hline
\end{tabular}

Note. Some models included more than one attribute (for example, a model may be both angled and 20 sided).

The results of the clay model virus task showed that students' concepts of viruses moved from conceptions of bumpy, round, two-dimensional images to conceptions that were more typically three-dimensional, angular, 20-sided, and spherical with angles (like the isocahedral models encountered during instruction). Table 2 shows the frequency of attributes for clay virus models pre- and postinstruction.

Similar types of representations were found in students' drawings of viruses (Table 3). Students' predrawings changed from cell or amoebalike images (Figure 4) to postdrawings of angled icosohedrals (Figure 5).

Table 3

Frequencies of attributes in virus drawing

\begin{tabular}{lcc}
\hline Attribute & Preinstruction & Postinstruction \\
\hline Angled & 0 & 20 \\
2D & 32 & 26 \\
3D & 0 & 15 \\
Irregular & 12 & 1 \\
Bumps/dimples & 0 & 13 \\
Appendages & 0 & 6 \\
Angular sphere & 0 & 17 \\
20-sided & 0 & 4 \\
Cell-like & 13 & 1 \\
Phagelike & 0 & 1 \\
Rounded icosohedral & 0 & 7 \\
Round & 13 & 4 \\
Amoebalike & 12 & 1 \\
Cilliatelike & 4 & 0 \\
Do not know & 11 & 0 \\
\hline
\end{tabular}

Note. Some models included more than one attribute (for example, a model may be both angled and 20-sided). 

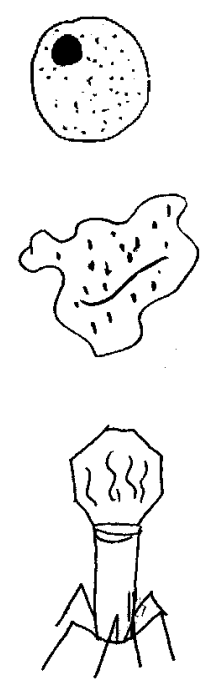

Figure 4. Examples of preinstruction drawings.

The clay models and the drawings showed an increase in the number of dimensions represented. After instruction, 35\% of the students' drawings denoted three dimensions, whereas none of the preinstruction drawings indicated more than two dimensions. Slightly over $16 \%$ of the drawings indicated knowledge of the bumpy surface features of the adenovirus after instruction.

Changes in students' concepts of the dimensionality of viruses were further noted in the descriptions students gave on the written pre- and postknowledge tests. Students' responses were coded as three-dimensional or two-dimensional according to the language used in the written description. For example, descriptions such as "look round" or "long" were coded as twodimensional. Student descriptions were coded as three-dimensional when students either said they were three-dimensional or referred to objects that were clearly three-dimensional, such as "like a mountain," "like a 20-sided die," and "look like pimples." When students' responses failed to describe any aspect of the dimensionality of the virus structure, the response was coded as "no dimensions." Examples of no dimension responses were "alive and can transfer," and "They look like bad diseases." A second researcher coded the entire dataset for an interrater agreement of
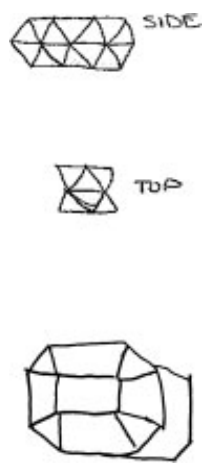

Figure 5. Examples of postinstruction drawings. 
Table 4

Dimensionality of students' descriptions of viruses

\begin{tabular}{lcc}
\hline & Preinstruction & Postinstruction \\
\hline No dimension & 23 & 3 \\
2D & 12 & 12 \\
3D & 6 & 26 \\
\hline
\end{tabular}

Note. A $2 \times 2$ chi-square test comparing the frequencies for the $2 \mathrm{D}$ or No Dimensions versus $3 \mathrm{D}$ across the pre- and posttests was significant, $\chi(1,41)=18.5, p<.01 . N 7=41$.

$88 \%$. Table 4 shows frequencies of virus dimensionality mentioned in students' responses. As noted in students' drawings, over half the students' descriptions of viruses included three dimensions.

Analogies students used to describe viruses moved from preinstruction references such as "circles," "tiny organisms," and "curvy lines" to postinstruction references such as "dice," "spaceship," "robot," "knots," and "rocket." The spatial dimensions represented in their language provide further evidence of changes in students' conceptions of virus structures.

\section{Knowledge of Scale}

Before instruction, $40 \%$ of students indicated they had no idea what a nanometer was and were unable to name anything that would be measured in nanometers. When students had a preconception of a nanometer, they had an idea that nanometers are part of a meter but typically were unable to explain what part of a meter. When asked to name something normally measured in nanometers, most students indicated that they did not know or gave responses that were inaccurate, such as "skin follicles," "cells," and "bacteria." The instruction during the study focused students' attention on the relative size of atoms, viruses, and bacteria. Table 5 shows changes in students' knowledge of nanometers. A correct response was coded when students gave accurate examples of one or more things that would be measured at the nanoscale. Responses were coded as mixed when students noted one or more correct items but also included an incorrect item (such as a response of "viruses," "DNA," and "cells"). Responses were coded as incorrect when students named items that were clearly not measurable at the nanometer scale (such as protists).

\section{Knowledge of Microscopy}

Before instruction, students typically could only name the light microscope they had used previously in school (70\%) and only a few students could name the electron microscope (20\%).

Table 5

Students' understandings of nanometers

\begin{tabular}{lcccc}
\hline & Correct & Mixed & Do Not Know & Incorrect \\
\hline Preinstruction & 8 & 2 & 30 & 2 \\
Postinstruction & 13 & 20 & 1 & 4 \\
\hline
\end{tabular}

Note. Chi-Square (comparing correct/mixed understandings with incorrect/do not know) $(1,43)=29.4, p<.01$. 
After instruction, students named not only the light microscope (25\%) but also the AFM (50\%), and electron microscope (21\%). Students' newspaper reports provided evidence that students' conceptual understandings went beyond the naming of microscopes to include knowledge of how the $\mathrm{nM}$ and AFM operate, the impact of tip size on images produced, and the potential to use the AFM to ask new questions.

Tammy, one of the students, explained the use of the nM and the AFM in her report:

[T] he nanoManipulator ... is a little box with a pen attached to it. The box is attached to a computer. When we walked in, we saw a purple bumpy surface on the computer screen. You then touched the pen to the surface by looking at the computer. Rapidly you start to feel the pen jump and vibrate as it makes you feel as if you are touching the virus.

Darren, another student, wrote:

The nanoManipulator is pretty complicated to explain. There was a colorful image on a computer screen. The image looked like a globe with the actual elevations on it. It was a flat surface with different lumps. We used a handheld pen to move a point on the screen around. When you moved the point over the lump, which is an actual virus, you could feel the surface of the virus. This can be very useful to scientists in figuring out how the virus attaches itself to other cells. I want to know how the virus breaks open to release the bad DNA.

Part of the instructional experiences involved having students create an image of a paper virus model and making a tracing of the virus with an ink pen attached to a simulated AFM that has different sizes of removable tips. Students such as Darron developed an understanding of how the AFM creates an image of the virus:

We used a simulator, which is a model with a tip that could be moved up and down and back and forth. We would lay our virus on the surface and move the needle all the way across the sides and top of the virus. At the same time a marker was attached and was drawing on a piece of paper the outline of the virus. When we were finished, we were able to see the beginning of the virus's image. This is how the Atomic Force Microscope works. It has a tip that goes back and forth across the surface and it puts all of the individual images into one picture of the virus.

About a quarter of the students described how the different-size tips alter the image of the virus. For example, Shelia wrote:

We made a virus out of paper and tape. The virus had 20 sides. We made the outline of the virus we made. This part was very interesting. We used a microscope picture to see what a virus looks like. We could only see the top of the virus .... We used a big tip and a small tip (on the simulator) to draw the diagram. The smaller tip showed more details.

Another participant, Theresa, wrote:

Dr. [the scientist] ... told us how the nanoManipulator worked and then let us trace over a paper virus with a big metal machine, that was just like the one (Atomic Force Microscope) in the lab. He explained to us why the virus we saw on the computer looked rounded and flat on the top. When we traced the paper virus with the machine, we saw that it could not draw all 20 sides the way that they were. 
In summary, the series of experiences with the nM, the AFM, and the simulator appeared to affect students' understandings. Students tended to move from a two-dimensional to a threedimensional concept of viruses. After instruction students were more likely to have some understanding of nanoscale and many were more knowledgeable about atomic force microscopy.

\section{Discussion}

The primary purpose of this exploratory study was to examine the effects of an educational experience built around a WWW-controllable nM-AFM on high school students' understandings of viruses. The results of this study showed that students' understandings of virus morphology and dimensionality changed as a result of the experience with the nM, the AFM, and the scientists. Students' preconceptions of viruses resembled images they had seen previously in textbooks and on television. Rua and Jones (1999) conducted a study of elementary, middle, and high school students' concepts of viruses and bacteria and found that students' images are derived from what they see in the media (television, print publications, and movies). The students in the present study represented viruses on the preassessments as looking like those typically seen in textbook diagrams. In addition, before using the $\mathrm{nM}$, students depicted viruses as having two dimensions. After students used the $\mathrm{nM}$, they depicted viruses as three-dimensional. These preliminary data suggest that haptics may enhance students' understandings of dimensionality. Dimensionality is scientific property that crosses scientific domains and is important in understanding topics such as geologic processes, anatomy, and molecular structure. The nM technology adds physical manipulation and an element of hands-on exploration to the study of things not visible with the naked eye, and allows students to explore properties such as dimensionality of very tiny objects.

New technological developments such as the nM system allow educators and students to investigate science in ways never before imagined. Science curricula typically have roots in printbased media and are built on previous scientific research that used relatively primitive technology. New innovations in technology have changed the tools of science and have the potential to challenge our views of the content of science curricula.

The rapid development of high-quality three-dimensional graphics and virtual reality software also opens up new worlds to science teachers. The potential for students to explore microworlds visually and physically is within our grasp. The challenge for researchers is to develop new ways to measure how these technological innovations influence students' learning.

In addition to changes in students' understandings of viruses, students in this study also increased their knowledge of microscale as a result of participating in these investigations. After instruction significantly more students had at least a partial understanding of nanometers. Scale is a difficult topic for students to understand; yet, it is a major theme that cuts across science disciplines (American Association for the Advancement of Science, 1993). Terms such as nanometer and nanotechnology are showing up in science fiction literature, popular science articles, and the general media. Helping students understand the meaning of nanoscale can encourage them to participate more meaningfully in postmodern society.

As a result of using the simulator and the $\mathrm{nM}$ and AFM, students began to develop an understanding of the limitations of trying to visualize in three dimensions an object lying flat on a surface. This was apparent in Shelia's comment: "We made a virus out of paper and tape ... we would lay our virus on the surface and move the needle all the way across the sides and top of the virus ....When we were finished we could see the beginning of the virus image." Some of the students' drawings reflected the smoothed images the microscope tip generates as it moves across the virus. Almost $19 \%$ of students drew two different visualizations of the virus image (top and side views) after instruction, whereas all students drew only one visualization in the preassessments. 
Even when students used the clay to create a model of a virus, $37 \%$ of the students made the preinstruction model two-dimensional by flattening the clay on a sheet of paper, whereas after the instruction only $16 \%$ made two-dimensional clay models. Use of the simulator and $\mathrm{nM}$ to move, roll, and probe virus models and actual viruses appears to have made a difference in the dimensionality of students' concepts of viruses.

A secondary purpose of the present research was to explore the impact of haptic information on learning. One of the unique features of the nanomanipulator is its ability to provide haptic information. Haptic information includes shape but also information about sensations of hardness, elasticity, friction, morphologic shape, and stickiness. Does such input help students learn about viruses? We sought to examine this issue by comparing students who received full haptic feedback and those who received a limited version in which they could feel the flat surface but could not feel the shape, hardness, stickiness, etc., of the viruses. We failed to find significant differences between the full haptic and limited haptic versions.

Several reasons probably account for this finding. One is that the small sample size meant that we had limited power to detect group differences. In addition, the assessments were not able to assess haptic features of viruses directly. The unique features of the overall experience may have overridden any impact of the haptic manipulation. It seems clear that further research is needed to examine how haptic experiences contribute to students' conceptual understandings. If students have haptic preferences or sensitivities for haptic modes of learning, how do these individual differences contribute to concept formation? We need additional studies that explore how haptics may be useful tools for students with a physical disability (such as sight impairment) or mental disability (such as difficulty processing written text). Furthermore, the development of new microscopes encourages us to reexamine science curricula as we find ways to educate students about the potential strategies that can be used to study very tiny objects. As Richard Feynman said, "[T] here is plenty of room at the bottom" for the study of the very, very, small world that exists at the nanoscale (Feynman, 1959).

\section{Limitations}

This study was exploratory in nature and the results should be viewed in light of the limitations of the study. It is not possible to separate the impact of the nM technology from the larger set of instructional experiences. It is also highly likely that the mere novelty of participating in this type of unusual instructional experience would alter students' motivation and interests. The study was conducted as part of regular classroom instruction and it was not a fully controlled study of haptic experiences. Further research is under way to control for the modified haptic experiences (making a paper virus and using the AFM similator) that students completed in the present study to allow us to investigate more fully how haptics affects learning.

This study was also limited by the brief amount of time students had to use the nM and AFM owing to the need to give all students access to the equipment. The writing task was a rich source of information for the research but was generally disliked by the students. As a result, even after encouragement, some students wrote little and did not elaborate on their ideas.

\section{Conclusions}

This study demonstrated the feasibility of incorporating high-technology WWW-controlled scientific equipment in high school classrooms. Most of the students were excited by the experiences, and the interviews and stories made clear that the sense of feeling a virus was an important aspect of the experience. Although we did not detect a difference in the haptic and 
modified haptic treatments, students in both groups developed more accurate concepts of virus morphology and moved from a two-dimensional to three-dimensional understanding of viruses. Students also developed more accurate understandings of nanometer scale. In addition, through use of an AFM, students gained an understanding of how probing microscopes function. These findings suggest that further investigation of the educational uses of the WWW-controllable $\mathrm{nM}-\mathrm{AFM}$ is warranted.

Appendix A

\section{Opinion Questionnaire}

\section{Preassessment Items}

1. I believe that doing science for a living would be a boring life.

2. I believe that doing science involves mostly memorizing things and getting the right answer.

3. I believe that scientists mainly do research on problems in which they must create or generate answers that cannot be known in advance.

4. I believe that real science consists of teams of women and men working together to carry out experiments to solve problems or understand better how things work.

\section{Additonal Items on the Postassessment}

5. I found using the $\mathrm{nM}$ and AFM frustrating.

6. This lesson on the $\mathrm{nM}$ and AFM was boring.

7. I was able to participate fully in this lesson on the $\mathrm{nM}$ and AFM.

8. This lesson on the nM and AFM was very interesting to me.

9. I believe I learned a lot about viruses by participating in this lesson on the nM and AFM.

10. Ibelieve my views of what science is and how it is done have changed by participating in this lesson.

\section{Appendix B}

\section{Interview Questionnaire}

1. What are the different types of microscopes that scientists use to look at things smaller than can be seen with the unaided eye?

2. Which of these types of microscopes could magnify something the most?

3. What metric units of measure do scientists use to measure viruses?

4. There are many types of viruses; two types are adenoviruses and tobacco mosiac viruses. What do you know about these viruses?

5. How are these viruses similar and different?

6. How many viruses put together would it take to equal the diameter of a human hair (approximately)?

7. Can you think of things that would normally be measured in nanometers? If so, please list.

8. Can you think of things that would normally be meaured in micrometers? If so, please list.

9. If you had not had the chance to use the AFM and the nM, what would you have missed learning?

10. What did you believe was the purpose of doing the AFM and $\mathrm{nM}$ activities and the other activities in this lesson? 
11. What questions did the lesson experience raise for you?

12. Please use this ball of clay and show me what a virus looks like.

\section{Postinterview Additional Questions}

1. How did you feel about this learning experience?

2. Was it frustrating?

3. Was it boring?

4. Were you able to participate fully?

5. Was it interesting?

6. Was it fun?

7. Was it intellectually challenging?

\section{References}

American Association for the Advancement of Science. (1993). Benchmarks for science literacy. New York: Oxford University Press.

American Institute of Physics. (1997). Using technology for education: Panel recommendations. American Institute of Physics Bulletin of Science Policy News, 107.

Andre, T. \& Phye, G.D. (1986). Cognition, learning, and education. In Phye, G.D. \& Andre, T. (Eds.), Cognitive classroom learning (pp. 1-20). Orlando, FL: Academic Press.

Feynman, R. (1959, December). There is plenty of room at the bottom. Presentation given at the meeting of the American Physical Society, and the California Institute of Technology. (Available on-line: http://www.zyvex.com/nanotech/feynman.html).

Heller, M., Calcaterra, J., Green, S., \& Brown, L. (1999). Intersensory conflict between vision and touch: The response modality dominates when precise, attention-riveting judgements are required. Perception and Psychophysics, 61, 1384-1398.

Hung, W. \& Chen, D. (1999). Technologies for implementing social constructive approaches in instructional settings. Journal of Technology and Teacher Education, 7, 235-256.

Jones, M.G., Superfine, R., \& Taylor, R. (1999). Virtual viruses. Science Teacher, 66, 48-50.

Katz, D. (1989). The world of touch. Hillsdale, NJ: Erlbaum.

Klatzsky, R., Lederman, S., \& Reed, C. (1987). There's more to touch than meets the eye: The salience of object attributes for haptics with and without vision. Journal of Experimental Psychology: General, 116, 356-369.

Linn, M., Shear, L., Bell, P., \& Slotta, J. (1999). Organizing principles for science education partnerships: Case studies of students' learning about "Rats in Space" and "Deformed Frogs." Educational Technology Research \& Development, 47, 61-84.

Mayer, R.E., Bove, W., Bryman, A., Mars, R., \& Tapangco, L. (1996). When less is more: Meaningful learning from visual and verbal summaries of science textbook lessons. Journal of Educational Psychology, 88, 64-73.

Mayer, R.E. (1989). Systematic thinking fostered by illustrations in scientific text. Journal of Educational Psychology, 81, 240-246.

Mayer, R.E., Steinhoff, K., Bower, G., \& Mars, R. (1995). A generative theory of textbook design: Using annotated illustrations to foster meaningful learning of science text. Educational Technology Research and Development, 43, 31-43.

Mayer, R.E. \& Sims, V.K. (1994). For whom is a picture worth a thousand words? Extensions of a dual-coding theory of multimedia learning. Journal of Educational Psychology, 86, 389-401.

National Research Council. (1996). National science education standards. Washington, DC: National Academy Press. 
Piller, C. (2000, February 3). Physicists announce micro-circuitry breakthrough. Raleigh, NC: News and Observer.

Paivio, A. (1971). Imagery and verbal processes. New York: Holt, Rinehart, Winston.

Paivio, A. (1986). Mental representations: A dual coding approach, New York: Oxford University Press.

Prain, V. \& Hand, B. (1999). Students' perceptions of writing for learning in secondary school science. Science Education, 83, 151-162.

Pressley, M. \& McCormick, C.B. (1995). Advanced educational psychology. New York: HarperCollins.

Rieber, L.P. (1990). Using computer graphics in science instruction with children. Journal of Educational Psychology, 82, 135-140.

Rieber, L.R. (1991). Animation, incidental learning, and continuing motivation. Journal of Educational Psychology, 83, 318-328.

Rieber, L.P. (1995). A historical review of visualization in human cognition. ETR\&D, 43, $45-56$.

Rotman, D. (1999). Will the real nanotech please stand up? Technology Review, 102, 47-53.

Rua, M. \& Jones, M.G. (1999, April). Pieces of the story: Students', teachers', and medical professionals' beliefs about bacteria and viruses. Paper presented at the American Educational Research Association Annual Meeting, Montreal, Canada.

Tulving, E. (1972). Episodic and semantic memory. In Tulving. E. \& Donaldson, W. Organization of memory (pp. 382-411). New York: Academic Press.

Windschitl, M. \& Andre, T. (1998). Using computer simulations to enhance conceptual change: The roles of constructivist instruction and student epistemological beliefs. Journal of Research in Science Teaching, 35, 145-160.

Yang, E.M., Greenbowe, T., \& Andre, T. (1999, March). Spatial ability and the impact of visualization/simulations software on learning electro-chemistry. Paper presented at the annual meeting of the National Association for Research on Science Teaching, Boston, MA. 